\title{
Joining of alumina by using polycarbosilane and aluminum foil
}

\author{
Ken'ichiro KITA, ${ }^{\dagger}$ Naoki KONDO, Yasuhisa IZUTSU* ${ }^{*}$ and Hideki KITA \\ National Institute of Advanced Industrial Science and Technology (AIST), \\ 2266-98 Shimo-shidami, Moriyama-ku, Nagoya 463-8560, Japan \\ *Stereo Fabric Research Association, 2266 Shimo-shidami, Moriyama-ku, Nagoya 463-8560, Japan
}

\begin{abstract}
This paper describes a novel experiment in which alumina was joined using polycarbosilane (PCS) and an aluminum foil. PCS was used to design the surface structure of alumina, and the aluminum foil enabled the formation of an area that included the alumina surface designed using PCS; this area could be joined to ceramic materials. A four-point bending test revealed that the flexural strength of both the silicon carbide $(\mathrm{SiC})$ and the silicon oxide $\left(\mathrm{SiO}_{2}\right)$ pieces that were obtained from alumina whose surfaces were modified to $\mathrm{SiC}$ or $\mathrm{SiO}_{2}$ increased, compared with the flexural strength of ceramics joined by alternative methods

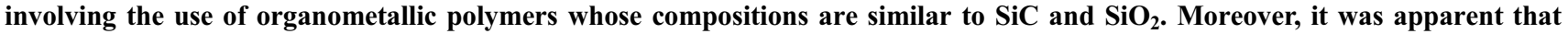
alumina was formed by the reaction of $\mathrm{SiO}_{2}$ with aluminum. However, traces of $\mathrm{Al}$ and $\mathrm{Si}$ remained in the joining area in both the $\mathrm{SiC}$ and $\mathrm{SiO}_{2}$ pieces.
\end{abstract}

(2012 The Ceramic Society of Japan. All rights reserved.

Key-words : Polycarbosilane, Si Carbide, Si Oxide, Alumina, Joining, Aluminum

[Received December 13, 2011; Accepted February 6, 2012]

\section{Introduction}

In recent years, considerable attention has been paid to the environmental impact of various materials in several fields, and a number of technologies for reducing this impact have been invented and reported. ${ }^{1), 2)}$ In the field of materials science, the environmental impact of ceramics is generally considered negligible owing to the fact that ceramics exhibit excellent properties such as low weight, high toughness, high heat resistance, high corrosion resistance, and high radiation resistance. ${ }^{3), 4)}$ Further, the environmental impact of certain materials (e.g., rare metals) used in high-temperature production processes can be effectively reduced by replacing these materials with their ceramic counterparts. However, it is very difficult to fabricate ceramic products on a large scale because a large furnace is required for their fabrication and they are expensive to prepare. In light of these problems, it is very important to conduct research on the joining of ceramics, and studies in this area of research have been reported. ${ }^{5)}$

Well-known processes used for joining ceramics include metallization and the use of an adhesive agent. ${ }^{6), 7)}$ The advantages of using an adhesive agent are that it enables the lowtemperature joining of ceramics, it can be applied to ceramics with complicated shapes, it allows joining without any cracks, and it prevents stress invariance during the joining process. ${ }^{8)}$ The disadvantages of using an adhesive agent are that it has a low thermal resistance and it can sometimes produce joints with inconsistent quality; this inconsistency in quality is attributed to many factors that affect the joining process. The advantages of metallization are that it does not require that the ceramic surfaces (herein, alumina surfaces) be ground before joining and it does require a particular machine for the joining process. ${ }^{9)}$ It should be noted that at room temperature, the bond between metals and alumina is strong; however, when alumina is heated to a certain temperature, this bond weakens. Therefore, a new joining method, which possesses advantages of metallization and the use of an adhesive agent, is required.

\footnotetext{
Corresponding author: K. Kita; E-mail: kita.kennichiro@aist.go.jp
}

In this study, we focused on using polycarbosilane (PCS) for designing the surface structure of alumina. PCS comprises active $\mathrm{Si}-\mathrm{H}$ groups that can bond with the other material to which it is to be joined, and it is well known that PCS is a precursor of the silicon carbide (SiC) ceramic. ${ }^{10)-12)}$ Therefore, PCS can be used to design the surface structure of alumina. We applied an aluminum foil to the alumina surface, and the surface was modified to $\mathrm{SiC}$ or silicon oxide $\left(\mathrm{SiO}_{2}\right)$ because aluminum and these modified surfaces can be converted to various ceramics such as alumina and mullite. ${ }^{13)}$ Moreover, the wettability of molten aluminum combined with $\mathrm{SiC}$ is greater than that of alumina. ${ }^{14)}$ The results of our experiment validate the effectiveness of the proposed joining method.

\section{Experimental procedure}

Figure 1 shows the outline of this experiment. Alumina pieces (length: $20 \mathrm{~mm}$, width: $30 \mathrm{~mm}$, and height: $20 \mathrm{~mm}$ ) were cut from bulk alumina supplied by Mitsui Kinzoku Corporation. The purity of these pieces was greater than $99.9 \%$, and they had an average grain size of approximately $2 \mu \mathrm{m}$. One surface of the alumina pieces, with an area of $600 \mathrm{~mm}^{2}$, was roughly ground. The following investigations were then carried out on the ground surface.

In our experiment, PCS (NIPUSI Type-A, Nippon Carbon, Japan) was dissolved in dehydrated toluene up to a concentration of $0.1 \mathrm{~mol} / \mathrm{L}$. The ground surfaces of the alumina pieces were dipped in toluene solution and dried using an air blower. After these alumina pieces were dipped in toluene solution a few times, they were cured at $253 \mathrm{~K}$ for $13.5 \mathrm{~h}$ under air flow after drying and were pyrolyzed at $1273 \mathrm{~K}$ for $1 \mathrm{~h}$ under an Ar flow. This process was carried out three times, and the pyrolyzed pieces were called the "SiC pieces." Then, some $\mathrm{SiC}$ pieces were heated at $1673 \mathrm{~K}$ for $1 \mathrm{~h}$ in air, and the heated pieces were called the " $\mathrm{SiO}_{2}$ pieces."

Two of the $\mathrm{SiC}$ pieces were selected, an aluminum foil with a thickness of approximately $11 \mu \mathrm{m}$ was placed between the ground surfaces of the pieces, and the pieces were heated at $1073 \mathrm{~K}$ for $2 \mathrm{~h}$ in vacuum. The abovementioned process was also carried out in the case of the $\mathrm{SiO}_{2}$ pieces. 


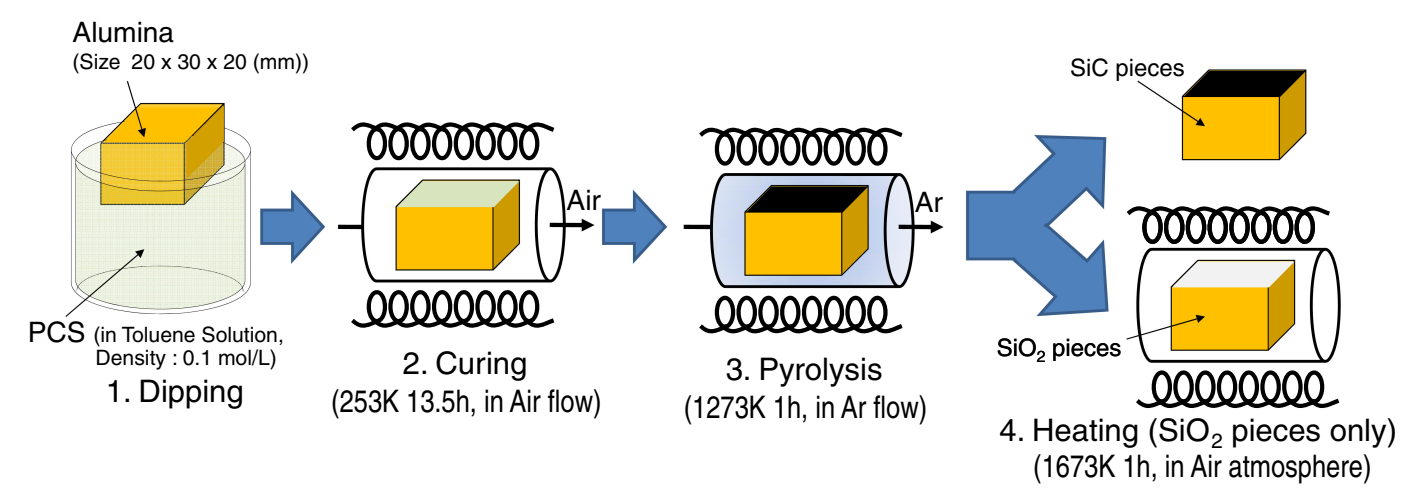

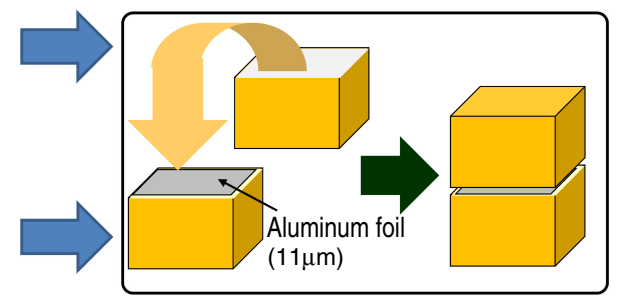

5. Pile

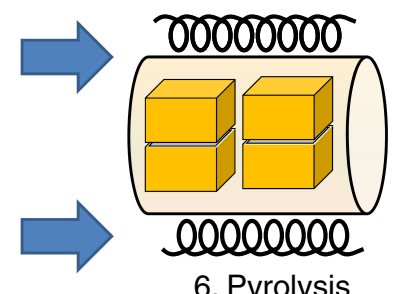

(1073K 2h, in Vacuum)

Fig. 1. (Color online) Outline of this experiment.
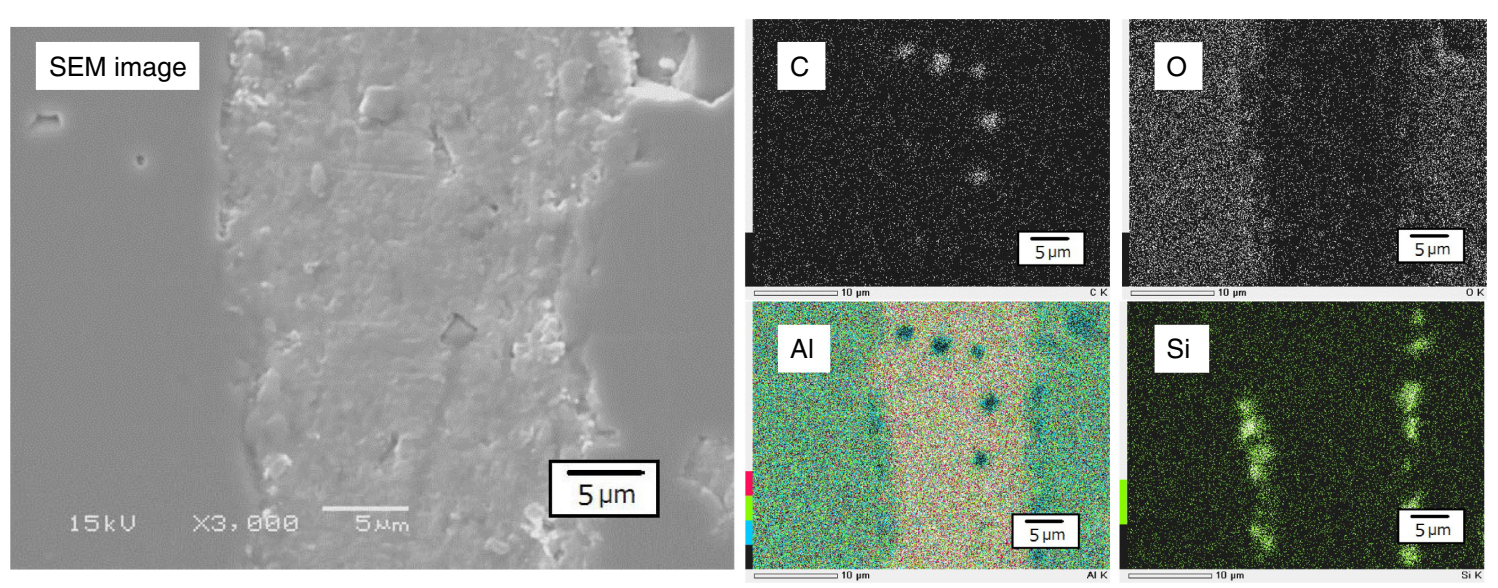

Fig. 2. (Color online) SEM image and EDS mappings of the cross section of the joining area of SiC pieces after heating at $1073 \mathrm{~K}$ (Left: SEM image, Right: EDS mappings).

After the completion of the abovementioned process, the heated pieces were cut in the shape of sticks following JIS $\mathrm{R} 1601$, the upper and lower spans were 10 and $30 \mathrm{~mm}$ long, respectively. The joining area in the pyrolyzed surface was observed by scanning electronic microscopy (SEM; JEM-5600, JEOL, Japan), energy dispersive X-ray spectroscopy (EDS; JEM2300, JEOL, Japan), and X-ray diffraction (XRD; RINT2500, Rigaku Corporation, Japan). After the observation, a four-point bending test was performed.

\section{Results and discussion}

After performing the joining experiment described above, a detailed investigation of the joining area was first carried out by SEM, EDS, and XRD. Figure 2 shows the SEM image and the EDS mappings of the cross section of the joining area of the $\mathrm{SiC}$ pieces after they were pyrolyzed at $1073 \mathrm{~K}$. The width of the joining area was approximately $30 \mu \mathrm{m}$, and the interface between the joining area and alumina was seamless. The EDS image showed that the Al peak in the joining area was very strong and that the Si peak in the joining area was mainly observed at the edge of the area. Moreover, some dots that indicate a decrease in the intensity of the Al peak were observed, and these dots suggest the existence of carbon. The existence of carbon in the joining area is expected because the surface of the joining area of the $\mathrm{SiC}$ pieces contained carbon.

Figure 3 shows the SEM image and the EDS mappings of the cross section of the joining area of the $\mathrm{SiO}_{2}$ pieces after they were heated to $1073 \mathrm{~K}$. The width of the joining area was approximately $20 \mu \mathrm{m}$. The intensity of the strong $\mathrm{Al}$ peak in the joining area was less than that of the Al peak shown in Fig. 2, and a strong Si peak was observed in most locations of the joining area. Moreover, tiny cracks along the border of the joining area were not observed in the sample. Although an aluminum foil with the same thickness was employed, the width of the joining area in the $\mathrm{SiC}$ pieces differed from that of the joining area in the $\mathrm{SiO}_{2}$ pieces. In addition, the intensity of 

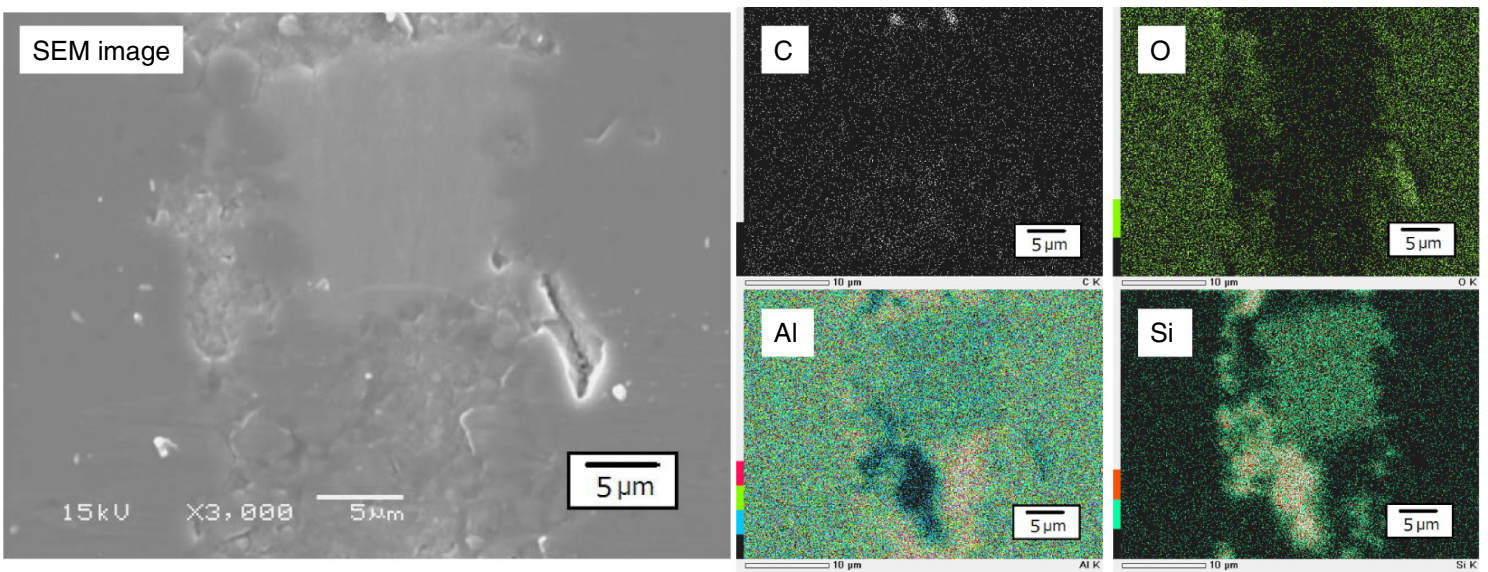

Fig. 3. (Color online) SEM image and EDS mappings of the cross section of the joining area of $\mathrm{SiO}_{2}$ pieces after heating at $1073 \mathrm{~K}$ (Left: SEM image, Right: EDS mappings).
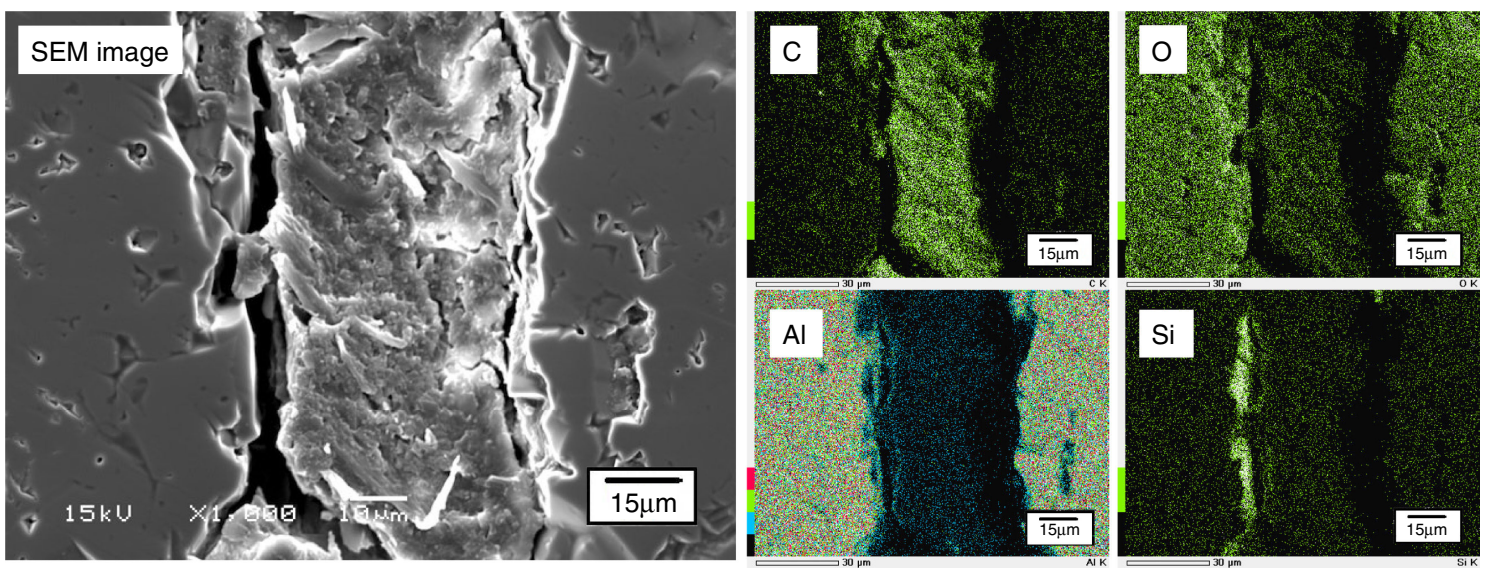

Fig. 4. (Color online) The SEM image and EDS mappings of the cross section of the joining failed area of SiC pieces after heating at $1073 \mathrm{~K}$ (Left: SEM image, Right: EDS mappings).
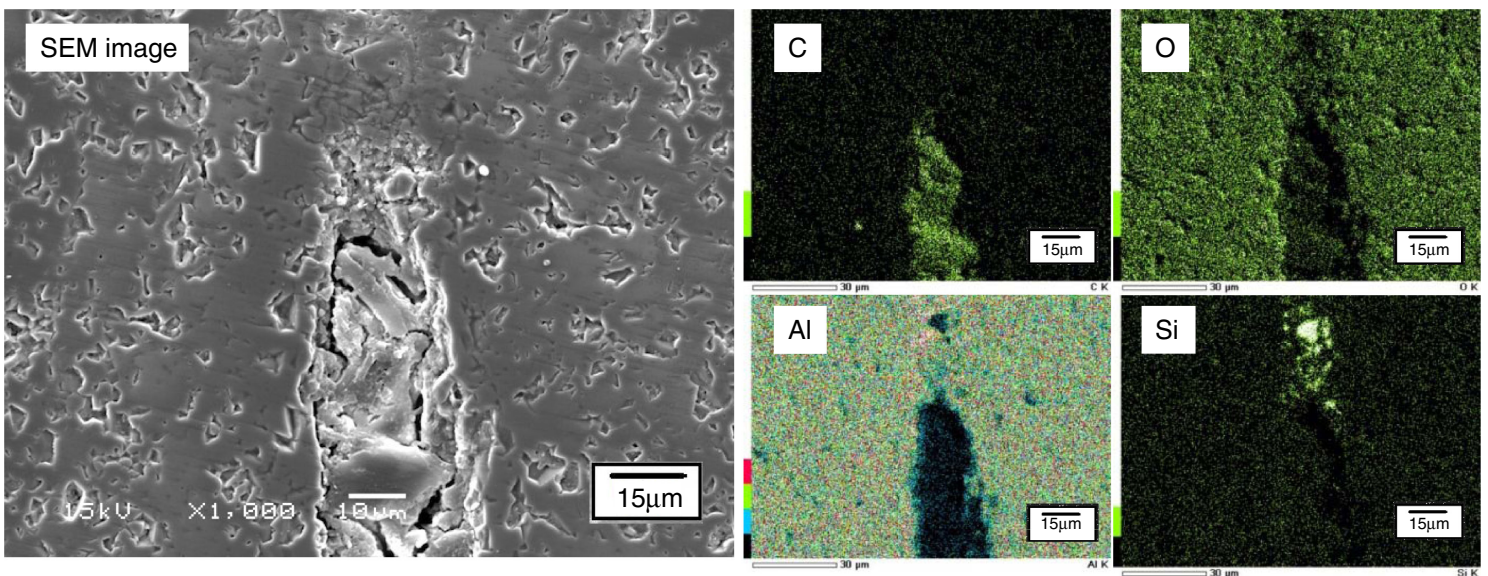

Fig. 5. (Color online) The SEM image and EDS mappings of the cross section of the joining failed area of $\mathrm{SiO}_{2}$ pieces after heating at $1073 \mathrm{~K}$ (Left: SEM image, Right: EDS mappings).

the $\mathrm{Si}$ peak in the joining area of the $\mathrm{SiO}_{2}$ pieces increased, and the Si peak was observed in only some locations of the joining area.

The joining areas identified for the $\mathrm{SiC}$ and $\mathrm{SiO}_{2}$ pieces are shown in Figs. 2 and 3, respectively; however, there were a few areas that were not suitable for joining. We also investigated these areas. Figures $\mathbf{4}$ and $\mathbf{5}$ show the SEM images and EDS mappings of cross sections of areas of the $\mathrm{SiC}$ and $\mathrm{SiO}_{2}$ pieces that were not suitable for joining, after these pieces were heated to $1073 \mathrm{~K}$. The SEM images showed cracks with a width of approximately $7 \mu \mathrm{m}$ arising between alumina and the joining area, as well as a number of cracks arising in the areas that were 


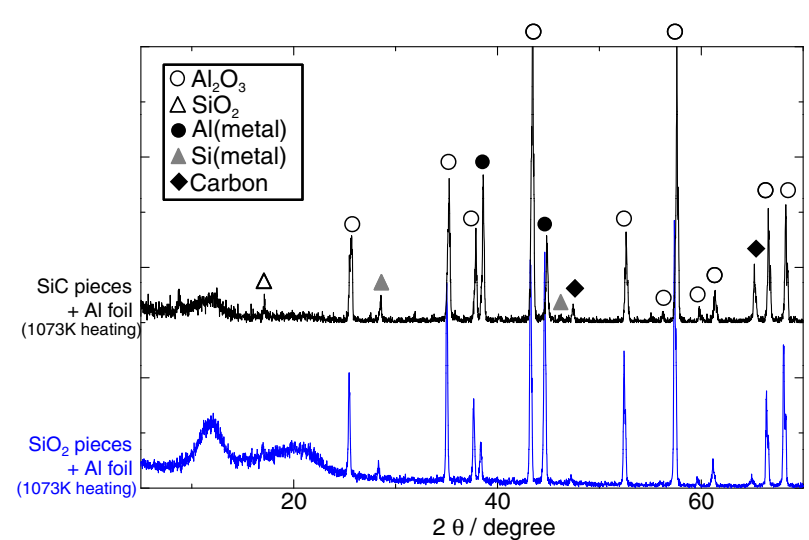

Fig. 6. (Color online) XRD spectra of the joining area of $\mathrm{SiC}$ and $\mathrm{SiO}_{2}$ pieces after heated at $1073 \mathrm{~K}$.

not suitable for joining. Moreover, the SEM images showed that these areas were dominated by the peak of the carbon atom, and not the peaks of $\mathrm{Al}$ and $\mathrm{Si}$ atoms. It is thought that the cracks were caused by carbon or carbon compounds.

Figure 6 shows the XRD spectra of the joining area of $\mathrm{SiC}$ and $\mathrm{SiO}_{2}$ pieces. These spectra mainly show the strong peaks of alumina, $\mathrm{SiO}_{2}, \mathrm{Al}, \mathrm{Si}$ and $\mathrm{C}$. Strong peaks derived from alumina (corundum) such as those at 35.0, 37.5, 43.1, and $57.2^{\circ}$ were observed in both spectra. However, we cannot exclude the possibility that these peaks were influenced by bulk alumina because the thickness of the joining areas was only less than $50 \mu \mathrm{m}$. Therefore, although from Fig. 3, it seems likely that an alumina layer was formed by the joining process, the formation of this layer could not be predicted from the data obtained from these spectra. The peaks at 47.5 and $65.0^{\circ}$ (not the $\mathrm{SiC}$ peaks) are expected to be the peaks of carbon or carbon compounds, and as shown in Figs. 4 and 5, these peaks are indeed the expected peaks because these figures suggest the existence of carbon compounds in the cracked joining area. The peaks at 38.5 and $44.5^{\circ}$ are the peaks of aluminum, and it appears that there was a considerable amount of aluminum in the joining process. The peaks at 28.1 and $44.1^{\circ}$ seem to be the peaks of metal Si.

The XRD spectrum of the $\mathrm{SiO}_{2}$ pieces shows a wide and continuous peak for $\theta=9.0-13.0^{\circ}$. Such a peak shows the existence of an amorphous compound, which was considered to be amorphous metal $\mathrm{Si}$ or $\mathrm{SiO}_{2} \cdot{ }^{15}$ ) Though a large amount of $\mathrm{Si}$ or $\mathrm{SiO}_{2}$ was considered to exist, few peaks suggest the existence of metal $\mathrm{Si}$ and $\mathrm{SiO}_{2}$. If the $\mathrm{Si}$ atoms in $\mathrm{SiO}_{2}$ are substituted for aluminum atoms, we will be able to understand why the thickness of the joining area in the $\mathrm{SiO}_{2}$ pieces was less than that of the joining area in the $\mathrm{SiC}$ pieces and why the strong peaks of $\mathrm{Si}$ were observed in the joining area of the $\mathrm{SiO}_{2}$ pieces. After this substitution, it is considered that the contents of $\mathrm{Al}$ and $\mathrm{SiO}_{2}$ will decrease and those of alumina and $\mathrm{Si}$ will increase.

The 4-point bending tests were carried out to analyze the flexural strength of the $\mathrm{SiC}$ and $\mathrm{SiO}_{2}$ pieces after joining, and the result is shown in Fig. 7, and the detail result is shown in Table 1. The alumina sample joined using PCS only was also considered for the sake of comparison. PCS mainly consists of $\mathrm{Si}, \mathrm{C}$, and $\mathrm{O}$ atoms when heated under air flow; therefore, PCS was thought be an ideal candidate for comparison with $\mathrm{SiC}$ and $\mathrm{SiO}_{2}$. Twelve samples of the $\mathrm{SiC}$ and $\mathrm{SiO}_{2}$ pieces were used in this test, and ten samples of PCS were used. The average flexural strength of the $\mathrm{SiC}$ pieces was $127.3 \mathrm{MPa}$, that of the $\mathrm{SiO}_{2}$ pieces

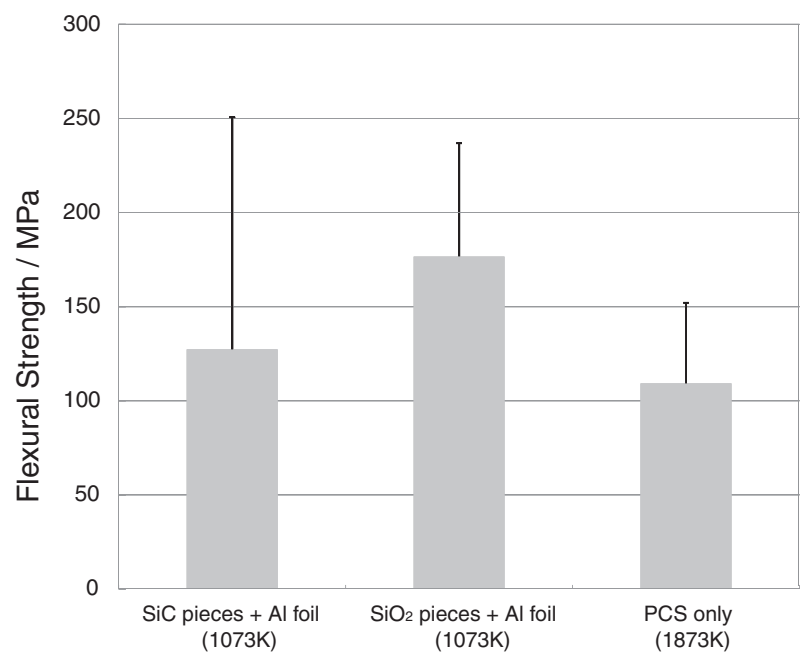

Fig. 7. The result of the 4 point bending tests of the samples.

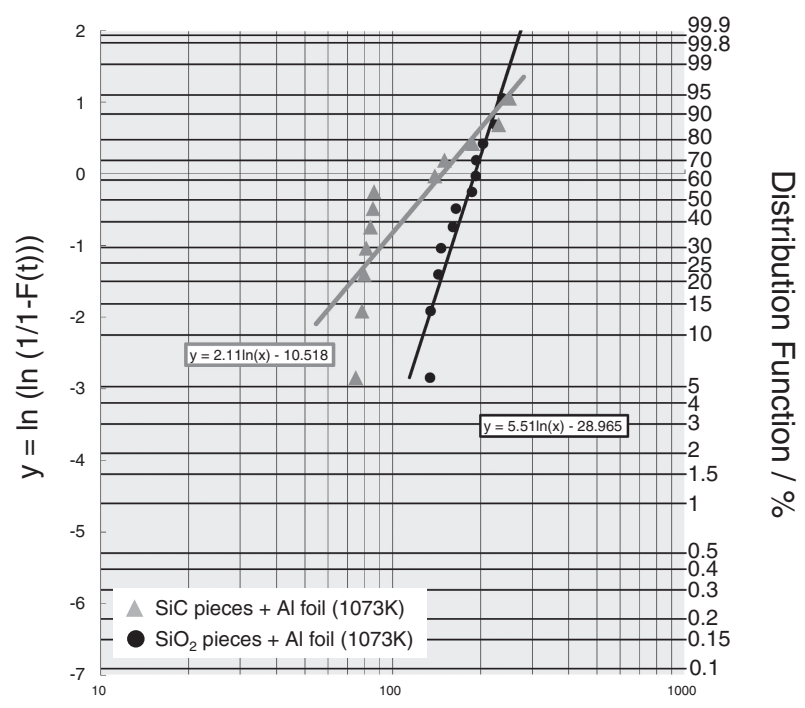

Flexural Strength / $\mathrm{MPa}$

Fig. 8. Weibull distribution of the 4 point bending tests of the samples.

was $176.5 \mathrm{MPa}$, and that of the PCS sample was $109.2 \mathrm{MPa}$. The average flexural strength of the $\mathrm{SiC}$ pieces was greater than that of the PCS sample by only approximately $10 \%$. However, the maximum flexural strength of the $\mathrm{SiC}$ pieces was $250.7 \mathrm{MPa}$ and that of the PCS sample was $152.0 \mathrm{MPa}$. Although the flexural strength of the SiC pieces was greater than that of the PCS samples, the distribution of the strength of the $\mathrm{SiC}$ pieces was distributed. On the other hand, the average flexural strength of the $\mathrm{SiO}_{2}$ pieces was considerably greater than that of the PCS sample; the maximum flexural strength increased to $236.9 \mathrm{MPa}$, and the distribution of the flexural strength was uniform.

The Weibull distribution plots of the $\mathrm{SiC}$ and $\mathrm{SiO}_{2}$ pieces during the 4-point bending tests are shown in Fig. 8. These plots were calculated using the median rank method, which is usually used for calculating Weibull plots. ${ }^{16)}$ The Weibull modulus of the sample of $\mathrm{SiC}$ pieces was 2.11 and that of the $\mathrm{SiO}_{2}$ pieces was 5.11. This result shows that $\mathrm{SiO}_{2}$ pieces are better for reducing unevenness of the tensile strength of joined materials. 
Table 1. Detail result of the 4 point bending tests

\begin{tabular}{lccc} 
& & & (Unit:MPa) \\
\hline \multicolumn{1}{c}{ Sample } & $\begin{array}{c}\mathrm{SiC} \text { pieces } \\
+\mathrm{Al} \text { foil } \\
(1073 \mathrm{~K})\end{array}$ & $\begin{array}{c}\mathrm{SiO}_{2} \text { pieces } \\
+\mathrm{Al} \text { foil } \\
(1073 \mathrm{~K})\end{array}$ & $\begin{array}{c}\text { PCS only } \\
(1873 \mathrm{~K})\end{array}$ \\
\hline Sample Number & 12 & 12 & 10 \\
Average & 127 & 177 & 109 \\
Maximum Strength & 251 & 237 & 152 \\
Minimum Strength & 74.6 & 134 & 60.8 \\
\hline
\end{tabular}

In this joining method, a direct reaction appeared to have occurred between the metal aluminum foil and the modified membrane on alumina. The reaction between $\mathrm{SiC}$ and molten $\mathrm{Al}$ produced metal $\mathrm{Si}$; the reaction formula is as follows:

$$
3 \mathrm{SiC}(\mathrm{s})+4 \mathrm{Al}(\mathrm{l}) \rightarrow \mathrm{Al}_{4} \mathrm{C}_{3}(\mathrm{~s})+3 \mathrm{Si}(\mathrm{s})
$$

This reaction occurred above $973 \mathrm{~K} .{ }^{17)}$ The joining was carried out at $1073 \mathrm{~K}$, and the existence of metal $\mathrm{Si}$ in the joining area was confirmed from the XRD spectrum shown in Fig. 6; therefore, it is considered that formula (1) represents the reaction that occurred during the joining. However, a previous study reported that the reaction occurred on the surface only, and a major amount of $\mathrm{SiC}$ and $\mathrm{Al}$ remained on both sides of $\mathrm{Al}_{4} \mathrm{C}_{3}$ when the temperature in the above reaction was less than $1473 \mathrm{~K} .{ }^{17)}$ The EDS mappings shown in Fig. 2 indicate that the Si peak mainly existed on the surface of the joining area and a strong $\mathrm{Al}$ peak occupied the interior of the joining area; therefore, the reaction was not considered to occur completely during this joining method. This joining method can be regarded as the Al metallization of alumina.

On the other hand, the reaction between Si oxide and metal Al is given by the following formula:

$$
\mathrm{SiO}_{2}+4 / 3 \mathrm{Al} \rightarrow \mathrm{Si}+2 / 3 \mathrm{Al}_{2} \mathrm{O}_{3}
$$

It is considered that this reaction occurs effectively above $1373 \mathrm{~K}^{18)}$ As shown in the XRD spectra of Fig. 6, the metal Si peak could be found in the joining area in spite of a joining temperature of $1073 \mathrm{~K}$; therefore, the above reaction occurred partially in this joining, and the mixed area containing $\mathrm{Al}$ and $\mathrm{Si}$ peaks seemed to represent a kind of reaction intermediate that resulted in the formation of aluminum-silicon oxide, as shown in reaction (2). This joining method can also be regarded as $\mathrm{Si}$ metallization of alumina, which is realized by using a polymer and metal $\mathrm{Al}$ and by controlling the joining temperature. The thickness of the modified membrane and the Al foil would then enable the joining area to either become just metal Si or become just the reaction intermediate.

\section{Conclusion}

From the results of this study, we found that alumina could be joined by using an aluminum foil and PCS, which is used to design the surface structure of alumina. We also found that the flexural strength of alumina could be considerably increased by using our method; this could not be achieved by other joining methods that involve the use of organometallic polymers whose compositions are similar to $\mathrm{SiC}$ and $\mathrm{SiO}_{2}$. The maximum flexural strength of the $\mathrm{SiC}$ pieces increased to $250.7 \mathrm{MPa}$; however, their average flexural strength increased by only $10 \%$ because of traces of aluminum remaining in the joining area of these pieces. On the other hand, the average and the maximum flexural strengths of the $\mathrm{SiO}_{2}$ pieces increased to 176.5 and $236.9 \mathrm{MPa}$, respectively, and it was considered that metal $\mathrm{Si}$ in the joining area enabled the increase in the strengths. Moreover, the cracks derived from the carbon compound in the joining areas were responsible for decreasing the flexural strength of both the pieces. In summary, it can be said that the process of joining ceramics using a metal foil and a compound that enables the design of the surface structure of the ceramics is effective and can be used in practice if carbon can be suitably removed and if an appropriate thickness of the metal foil can be determined.

Acknowledgement This research was supported by METI and NEDO, Japan, as part of the Project for the Development of Innovative Ceramics Manufacturing Technologies for Energy Saving.

\section{References}

1) M. D. Bovea, E. Diaz-Albo, A. Gallado, F. J. Colomer and J. Serrano, Mater. Des., 31, 35-41 (2010).

2) N. Tikui and P. Srichandr, J. Ceram. Soc. Japan, 118, 887-894 (2010).

3) S. Prochazka and R. M. Scanlan, J. Am. Ceram. Soc., 58, 72 (1975).

4) M. Fukushima, Y. Zhou, Y. Yoshizawa and K. Hirao, J. Ceram. Soc. Japan, 114, 1155-1159 (2006).

5) H. Kita, H. Hyuga and N. Kondo, J. Eur. Ceram. Soc., 28, 1079-1083 (2008).

6) L. S. D. Glasser, J. A. Gard and E. E. Lachowski, J. Appl. Chem. Biotechnol., 28, 799-810 (1978).

7) J. T. Klomp, Am. Ceram. Soc. Bull., 49, 204-211 (1970).

8) M. Itoh, E. Sugimoto and Z. Kozuka, Trans. Jpn. Inst. Metal., 25, 504-510 (1984).

9) M. Nicolas, J. Mater. Sci., 3, 571-576 (1968).

10) S. Yajima, J. Hayashi, M. Omori and K. Okamura, Nature, 261, 683-685 (1976).

11) T. Iseki, M. Narisawa, Y. Katase, K. Oka, T. Dohmaru and K Okamura, Chem. Mater., 13, 4163-4169 (2001).

12) M. Narisawa, T. Iseki, Y. Katase and K. Okamura, J. Am Ceram. Soc., 86, 227-233 (2003).

13) S. Maitra, R. Shibayan and A. K. Bandyapadhyay, Ind. Ceram., 24, 39-42 (2004).

14) K. Kita, N. Kondo, H. Hyuga, Y. Izutsu and H. Kita, J. Ceram. Soc. Japan, 119, 378-381 (2011).

15) Y. Hasegawa, J. Mater. Sci., 24, 1177-1190 (1989).

16) K. M. Entwistle, J. Mater. Sci., 28, 2007-2012 (1993).

17) T. Iseki, T. Kameda and T. Maruyama, J. Mater. Sci., 19, $1692-$ 1698 (1984)

18) T. Okunaga, J. Met. Mater. Miner., 19, 51-58 (2009). 